\title{
PENCARIAN RUTE TERPENDEK MENUJU TEMPAT WISATA MENGGUNAKAN METODE ALGORITMA GREEDY PADA DINAS PEMUDA OLAHRAGA KEBUDAYAAN DAN PARIWISATA KOTA CIREBON
}

\section{Badrudin Hadibrata dan Saeful Maudin}

Program Studi Teknik Informatika STIKOM POLTEK Cirebon

Email: bad_hadibrata@yahoo.co.id dan saefulmuadin335@gmail.com

\section{Abstract}

In daily life often travel from one place to another that will be desired. One of them is tourist attractions, tourist attractions are one of the interesting objects most frequently visited by tourists both local and outside the area because it is one of the interesting places to visit. Tourists will consider the criteria for tourist attractions such as location, beauty, the comfort of the environment, and beautiful scenery in the destination. Besides, the distance factor and the tourist attractions he visited are important things to consider so that it does not take too much time on the way to these attractions. In this study, a system was built to search for the shortest route to the tourist attractions based on the location of the tourist destination, to facilitate tourists in making the efficiency of travel distance, and the short time is taken to get to the tourist sites. Therefore it is very necessary to determine the shortest route between one place to another which will be the next tourist destination. This Geographic Information System uses the Greedy Algorithm method. So that this Geographic Information System can make it easier for visitors, especially local and foreign tourists to go to tourist attractions with short and fast travel routes and time efficiency without wasting a long time and getting the solution.

Keywords: Service Quality, Motivation, Consumer Decisions to Save Greedy Algorithms, Travel Routes, Tourist Attractions, Gographic Information Systems.

\footnotetext{
Abstrak

Dalam kehidupan sehari-hari sering dilakukan perjalanan dari suatu tempat ke tempat lain yang akan dituju. Salah satunya adalah tempat wisata, tempat wisata adalah salah satu objek menarik yang paling sering dikunjungi oleh para wisatawan baik lokal maupun luar daerah karna merupakan salah satu tempat yang menarik untuk di kunjungi. Wisatawan akan mempertimbangkan kriteria tempat wisata seperti lokasi, keindahan, kenyamanan lingkungan dan pemandangan indah di tempat wisata yang di tuju. Selain itu faktor jarak dan tempat wisata yang dikunjunginya adalah hal yang penting untuk dipertimbangkan agar tidak terlalu lama memakan waktu dalam perjalanan menuju ke tempat wisata tersebut. Pada penelitian ini dibangun sistem untuk melakukan pencarian rute terpendek menuju tempat wisata berdasarkan lokasi wisata yang akan di tuju dimana untuk memudahkan wisatawan dalam melakukan efisensi jarak perjalanan wisata dan
} 
waktu singkat yang di tempuh untuk sampai ke lokasi wisata. Oleh karena itu sangat diperlukan penentuan rute terpendek antar satu tempat ke tempat lain yang akan menjadi tujuan wisata selanjutnya. Sistem Informasi Geografis ini menggunakan metode Algoritma Greedy. Sehingga dengan Sistem Informasi Geografis ini dapat mempermudah para pengunjung khususnya wisatawan lokal maupun luar daerah untuk menuju tempat wisata dengan rute perjalanan tempat wisata yang singkat dan cepat dan efisiensi waktu tanpa membuang waktu yang lama dan mendapatkan solusinya.

Kata kunci: Kualitas layanan, Motivasi, Keputusan konsumen untuk menabung Algoritma Greedy, Rute Perjalanan, Tempat Wisata, Sistem Informasi Gografis.

\section{Pendahuluan}

Kota Cirebon merupakan salah satu tempat tujuan wisata di Jawa Barat yang dikunjungi oleh para wisatawan baik lokal maupun luar daerah kota cirebon, banyak tempat wisata yang ditawarkan di kota cirebon mulai dari wisata religi, sarana hiburan hingga kesenian daerah cirebon, tidak heran ketika weekend maupun libur hari raya banyak wisatawan berlibur untuk menghabiskan waktu berliburnya ditempat wisata.

Kecepatan perkembangan teknologi masuk kesemua lini dan sendi aktivitas manusia baik pribadi atau kelompok (badan). Jika dulu manusia dalam berkomunikasi harus selalu bertatap muka, tetapi kini komunikasi terjadi tanpa ada batas ruang dan waktu (Abdurokhim, 2016). Ketika pengunjung ingin menuju ke tempat wisata sangat dimudahkan dengan akses jalur yang tersedia di google maps ketika menuju tempat wisata yang terbaru khsususnya kota cirebon. Dengan akses google maps pengunjung atau wisatawan mudah menentukan lokasi wisata di kota cirebon baik yang ramai di kunjungi maupun yang tidak padat pengunjung. Namun, karena melonjaknya jumlah wisatawan yang membuat jalan menuju ke tempat wisata tersebut menjadi macet.

Terjebak dalam kemacetan pastinya membuat seseorang menjadi jenuh dan bosan, sehingga mereka akan berusaha mencari cara agar perjalanan mereka menjadi tidak terhambat dan sampai ke tempat tujuan dengan waktu yang singkat dan cepat. Salah satu solusinya yaitu dengan mengetahui rute alternatif tercepat agar terhindar dari kemacetan. Rute alternatif tercepat ini berguna untuk mendapatkan jarak dan waktu tempuh yang optimal dari tempat asal menuju tempat tujuan tanpa terhambat oleh kemacetan yang disebabkan melonjaknya wisatawan.

Dengan mempermudah wisatawan untuk mengakses tempat wisata dengan jalur yang cepat maka penerapan Sistem Informasi Geografis (SIG) berbasis web merupakan salah satu langkah atau cara untuk membantu para wisatawan dalam mengakses tempattempat wisata yang ada di Kota Cirebon. Sistem ini nantinya akan dirancang agar pengguna dapat mengakses dan memperoleh navigasi rute tempat-tempat wisata di kota Cirebon, melalui perangkat Smartphone serta bantuan web dengan mengimplementasi Algoritma Greedy, sehingga mempercepat pengaksesan tempat wisata.

Algoritma Greedy merupakan algoritma yang membentuk solusi langkah per langkah. Pada setiap langkah tersebut akan dipilih keputusan yang paling optimal. 
Sebuah metode yang dapat memecahkan persoalan optimasi dengan cara bertahap melalui alur yang selalu berkembang hingga pemecahan permasalahan dapat teratasi. Algoritma Greedy dapat memilih sebuah rute yang diambil dahulu untuk memberikan suatu alternatif lokal agar menghasilkan alternatif optimal dengan menyeluruh sehingga diperoleh rute tercepat dari lokasi awal hingga lokasi yang dituju.

Algoritma Greedy memiliki pendekatan untuk membangun solusi secara bertahap melalu urutan yang terus berkembang sampai solusi dari masalah telah tercapai (Levitin \& Mukherjee, 2007). Greedy memberikan alternatif optimal lokal dengan harapan setiap alternatif lokal menghasilkan alternatif global yang optimal secara keseluruhan. Algoritma Greedy dapat menyelesaikan Travelling Salesman Problem dengan menghitung nilai lokal optimal setiap mengunjungi kota dan mendapatkan nilai optimasi global pada akhir perjalanan.

(Lukman \& AR, 2011) Algoritma Greedy dalam penelitian terdahulu dapat diimplementasikan dalam melakukan optimasi jarak seperti dalam menentukan jarak terdekat atau shortest path dan Travelling Salesman Problem (TSP). TSP merupakan representasi masalah dalam penelitian ini yaitu menentukan rute perjalanan terpendek antara hotel dengan daya tarik wisata setelah mengunjungi seluruhnya. Prinsip Utama Algortima Greedy Prinsip utama algoritma greedy adalah "take what you can get now". Maksud dari prinsip tersebut adalah pada setiap langkah dalam algoritma greedy, diambil keputusan yang paling optimal untuk langkah tersebut tanpa memperhatikan konsekuensi pada langkah selanjutnya. Solusi tersebut disebut dengan optimum lokal.

Selain itu Algoritma Greedy juga membuat beberapa pilihan terbaik yang didapat sehingga wisatawan dapat mencari tempat wisata dengan rute perjalanan terpendek. Berdasarkan fenomena permasalahan yang ada sebagai berikut:

1. Para wisatawan kesulitan untuk mengakses jalur rute terdekat ke tempat objek wisata di kota cirebon yang akan dikunjungi.

2. Kurangnya media informasi mengenai rute perjalanan terdekat menuju tempat wisata.

3. Dibutuhkannya jalur alternatif menuju tempat wisata dengan jarak tempuh yang singkat.

Tujuan penelitian ini dengan menerapkan Algoritma Greedy untuk pencarian rute terpendek menuju tempat wisata di kota Cirebon yang diharapkan untuk dapat memberikan jalur alternatif menuju tempat wisata agar akses menuju tempat wisata di kota Cirebon lebih cepat dan efektif.

\section{Metode Penelitian}

Penelitian ini dilakukan supaya dapat mengetahui rute terpendek menuju tempat wisata dengan menggunakan metode Algoritma Greedy pada Dinas Pemuda Olahraga Kebudayaan Dan Pariwisata di Kota Cirebon. Jenis penelitian yang akan dilaksanakan dalam penelitian ini merupakan penelitian kuantitif, Populasi dan Sampel Penelitian Populasi adalah sebagai keseluruhan obyek penelitian (Arikunto \& Yuliana, 2008). 


\section{Hasil dan Pembahasan}

Nama lokasi titik awal adalah Stikom Poltek Cirebon menuju tempat lokasi tujuan adalah Makam Pangeran Suryanegara, sedangkan nama lokasi disimbolkan dengan huruf seperti pada tabel 1

Tabel 1 Data Sample Titik Awal Lokasi - Titik akhir Lokasi

\begin{tabular}{cc}
\hline Node & Nama Jalan \\
\hline A & Stikom Poltek Cirebon \\
\hline B & Jl. Brigjend Darsono \\
\hline C & Jl. Ir. H. Juanda \\
\hline D & Jl. Cipto \\
\hline E & Jalur Lohbener \\
\hline F & Jl. Jend. Sudirman \\
\hline G & Gang 1 \\
\hline H & Gang 2 \\
\hline I & Gang 3 \\
\hline J & Makam Pangeran Suryanegara \\
\hline
\end{tabular}

Lokasi dari titik A sampai dengan tiik $\mathrm{J}$ dan bobot tiap tiap sisi (bobot menyatakan jarak dari titik satu ke titik yang lain).

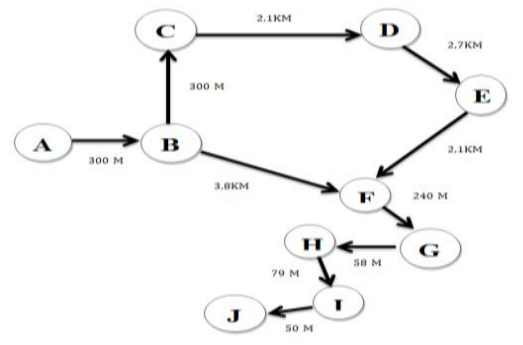

Gambar 2 Peta Jarak Tempat Wisata

Lintasan pertama yang harus dipilih adalah dari Titik A ke Titik B dengan bobot 300 meter, ditunjukan pada gambar 3.

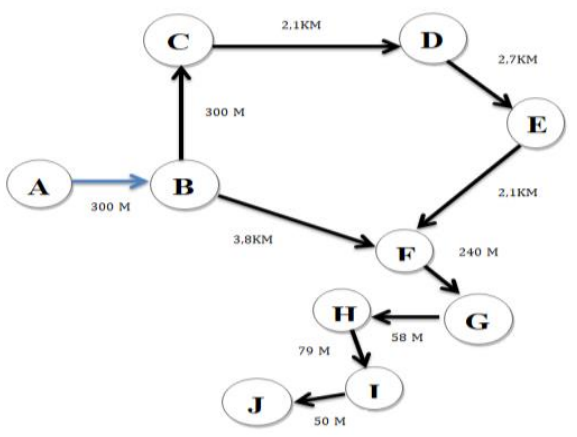

\section{Gambar 3 Rute yang di pilih titik A ke B.}

Selanjutnya memilih sisi yang berdekatan dengan titik $A B$, yaitu titik $B C$ dengan bobot 300 meter dan BF dengan bobot 3,8 Km. sehingga memilih titik BC dan BF karena ada 2 pilihan titik seperti pada gambar 4. 


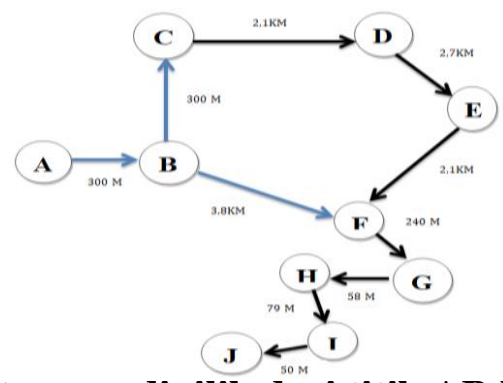

Gambar 4 Rute yang dipilih dari titik AB ke BC atau BF

Selanjutnya memilih titik yang berdekatan dengan titik $\mathrm{AB}$, yaitu titik $\mathrm{BC}$ dengan bobot $300 \mathrm{~m}$ atau $\mathrm{BF}$ dengan bobot $3,8 \mathrm{Km}$. Jadi memilih titik BC karena mempunyai nilai bobot lebih kecil, ditunjukan pada gambar 5 .

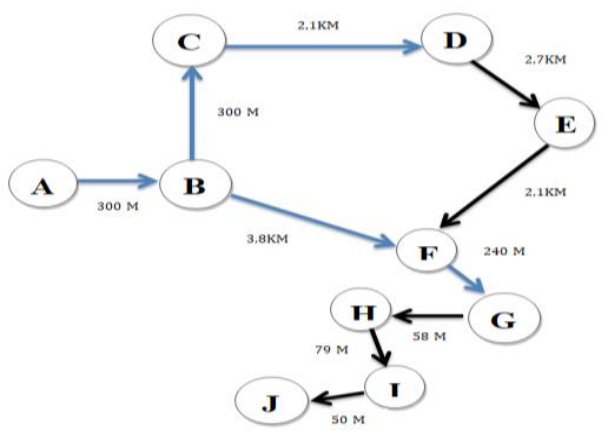

\section{Gambar 5 Rute yang dipilih dari titik AB ke BC dan BF}

Selanjutnya memilih titik yang berdekatan dengan titik BC yaitu titik CD dengan bobotnya 2,1 Km. Titik BF berdekatan dengan titik FG jadi bobotnya 240 meter.

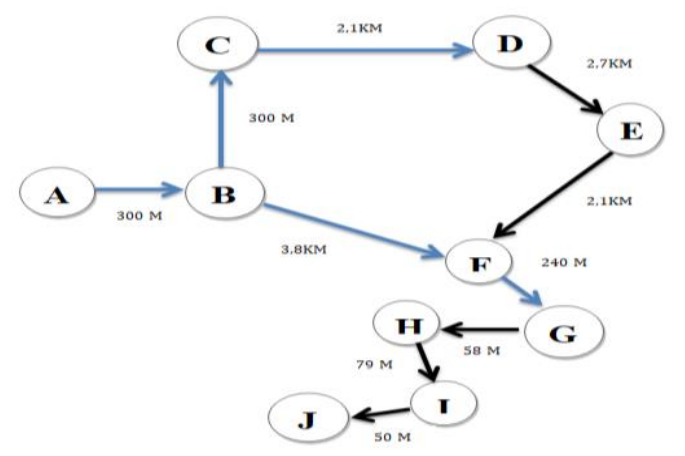

Gambar 6 Rute yang dipilih dari titik CD dan BF

Selanjutnya memilih titik yang berdekatan dengan titik CD yaitu titik DE dengan bobot $2,7 \mathrm{Km}$, seperti gambar 7 . 


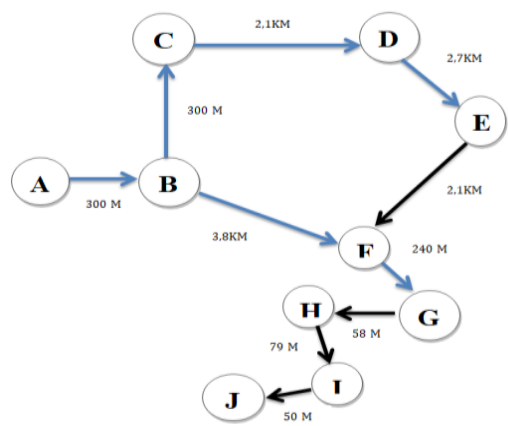

Gambar 7 Rute yang dipilih dari titik CD ke DE.

Selanjutnya memilih titik yang berdekatan dengan titik DE yaitu titik EF dengan bobo $2,1 \mathrm{Km}$, seperti gambar 8 .

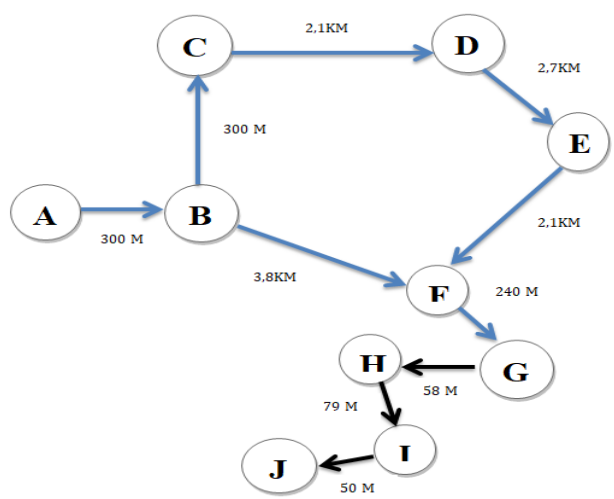

Gambar 8 Rute yang dipilih dari titik DE ke EF.

Selanjutnya memilih titik yang berdekatan dengan titik EF yaitu titik FG dengan bobo 240meter, seperti gambar 9 .

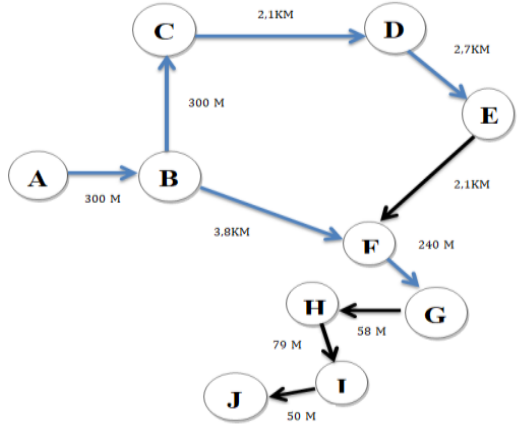

Gambar 9 Rute yang dipilih titik FG

Selanjutnya memilih dari titik FG ke GH dengan bobot nilai 58meter, seperti gambar 10. 


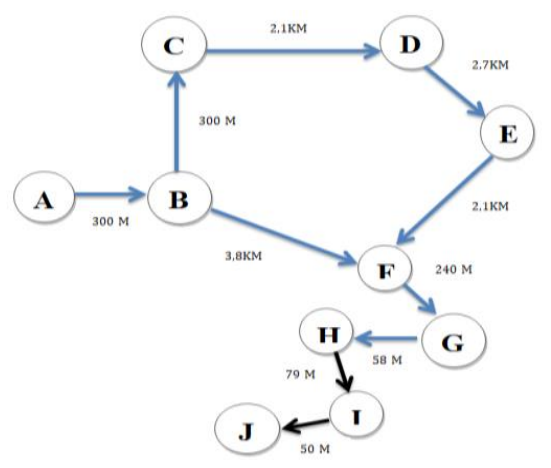

Gambar 10 Rute yang dipilih titik GH

Selanjutnya memilih dari titik GH ke HI dengan bobot nilai 79meter, seperti gambar 11
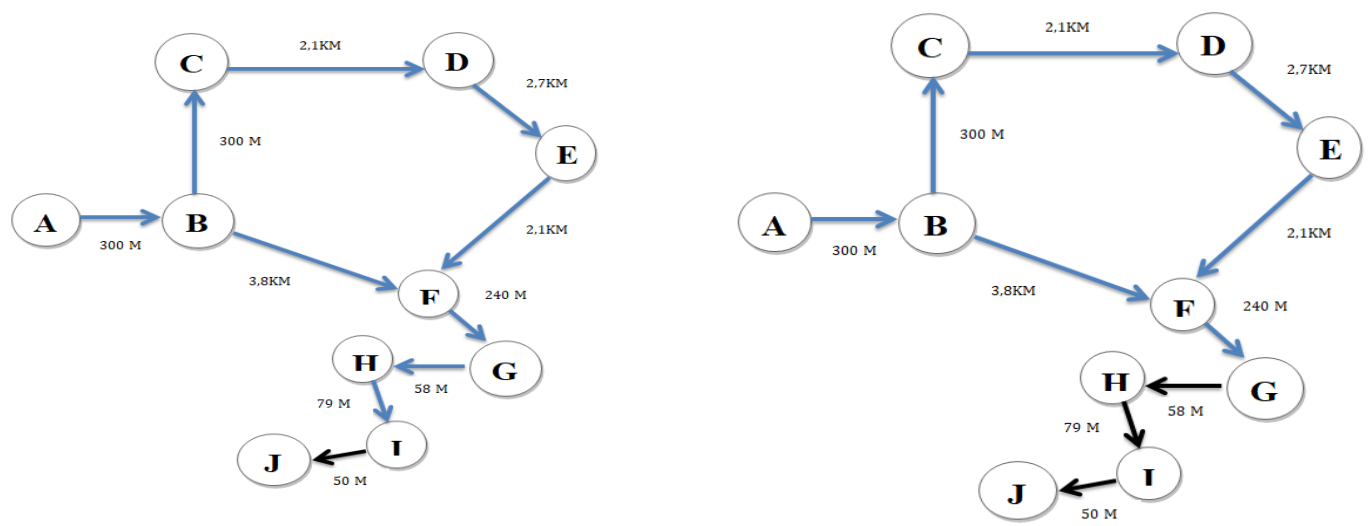

Gambar 11 Rute yang dipilih titik HI

Selanjutnya memilih dari titik HI ke IJ dengan bobot nilai 50 meter, seperti gambar 12

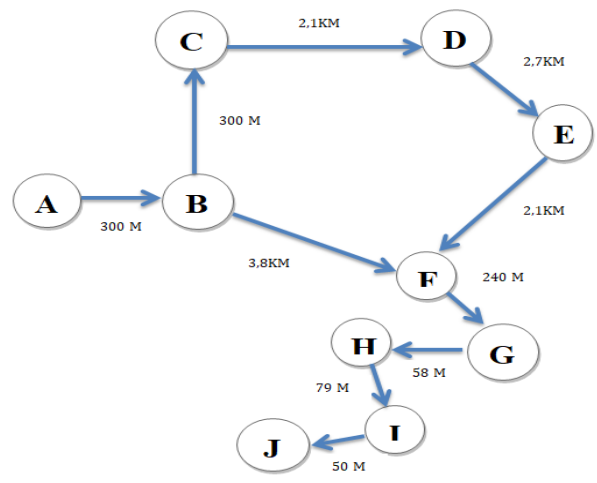

Gambar 12 Rute yang dipilih titik IJ

Berdasarkan Gambar di atas rute terpendek yang harus di tempuh ada 2 pilihan :

1. Jalur ke 1 adalah $\mathrm{AB} \rightarrow \mathrm{BF} \rightarrow \mathrm{FG} \rightarrow \mathrm{GH} \rightarrow \mathrm{H} \rightarrow \mathrm{IJ}$.

2. Jalur ke 2 adalah $\mathrm{AB} \rightarrow \mathrm{BC} \rightarrow \mathrm{CD} \rightarrow \mathrm{DE} \rightarrow \mathrm{EF} \rightarrow \mathrm{FG} \rightarrow \mathrm{GH} \rightarrow \mathrm{HI}$ IJ. 
Maka perhitungan optimasi dengan algoritma greedy adalah sebagai berikut :

Tabel 2 perhitungan optimasi algoritma greedy

\begin{tabular}{c|c}
\hline Jalur 1 & Jalur 2 \\
\hline $\mathrm{A}-\mathrm{B}=300 \mathrm{M}$ & $\mathrm{A}-\mathrm{B}=300 \mathrm{M}$ \\
\hline $\mathrm{B}-\mathrm{F}=3,8 \mathrm{Km}$ & $\mathrm{B}-\mathrm{C}=300 \mathrm{M}$ \\
\hline $\mathrm{F}-\mathrm{G}=240 \mathrm{M}$ & $\mathrm{C}-\mathrm{D}=2,1 \mathrm{Km}$ \\
\hline $\mathrm{G}-\mathrm{H}=58 \mathrm{M}$ & $\mathrm{D}-\mathrm{E}=2,7 \mathrm{Km}$ \\
\hline $\mathrm{H}-\mathrm{I}=79 \mathrm{M}$ & $\mathrm{E}-\mathrm{F}=2,1 \mathrm{Km}$ \\
\hline $\mathrm{I}-\mathrm{J}=50 \mathrm{M}$ & $\mathrm{F}-\mathrm{G}=240 \mathrm{M}$ \\
\hline & $\mathrm{G}-\mathrm{H}=58 \mathrm{M}$ \\
\hline & $\mathrm{H}-\mathrm{I}=79 \mathrm{M}$ \\
\hline & $\mathrm{I}-\mathrm{J}=50 \mathrm{M}$
\end{tabular}

Dihasilkan optimasi sebagai berikut :

Jalur $1: 300 \mathrm{~m}+3,8 \mathrm{Km}+240 \mathrm{~m}+58 \mathrm{~m}+79 \mathrm{~m}+50 \mathrm{~m}=7,01 \mathrm{Km}$

Jalur $2: 300 \mathrm{~m}+300 \mathrm{~m}+2,1 \mathrm{Km}+2,7 \mathrm{Km}+2,1 \mathrm{Km}+240 \mathrm{~m}+58 \mathrm{M}+79 \mathrm{M}+50 \mathrm{~m}$ $=10,41 \mathrm{Km}$

Maka dari 2 pilihan rute terpendek yang ada dalam penelitian ini dan diperoleh hasil rute terpendek dari Lokasi A Menuju Lokasi J dengan urutan Jalur 1 adalah A-BF-G-H-I dan Jalur 2 adalah A-B-C-D-E-F-G-H-I-J dan dihasilkan rute terpendek yaitu dengan jarak tempuh 7,01 Km dari Lokasi A menuju Lokasi J dengan melewati Jalur 1.

\section{a. Halaman admin}

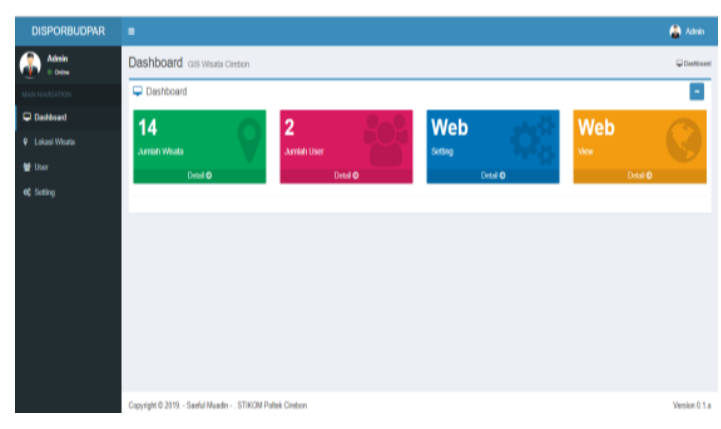

\section{b. Pencarian Rute}

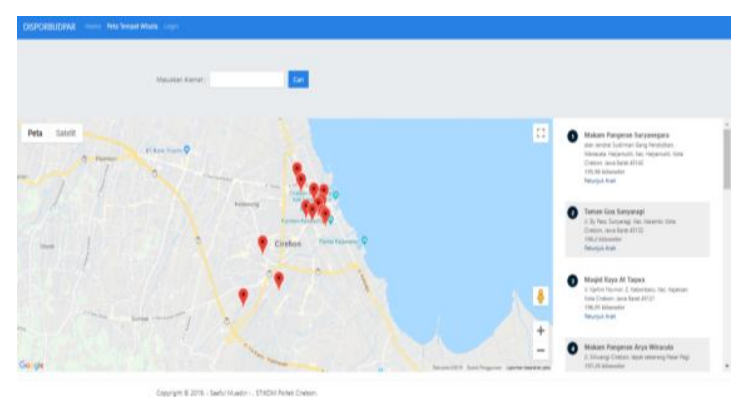

\section{Kesimpulan}

Dari uraian yang telah dijelaskan sebelumnya dapat diambil suatu kesimpulan dari sistem informasi geografis pencarian rute terpendek menuju tempat wisata menggunakan metode algoritma greedy pada dinas pemuda olah raga kebudayaan dan pariwisata kota cirebon sebagai berikut:

1. Aplikasi sistem informasi geografis pencarian rute terpendek menuju tempat wisata menggunakan metode algoritma greedy dapat mempermudah pengunjung untuk menentukan rute terpendek menuju lokasi tempat wisata yang akan dikunjungi dari lokasinya berada. 
Badrudin Hadibrata dan Saeful Maudin

2. Sistem yang dibuat dapat membantu para pengunjung untuk menentukan rute terpendek berdasarkan jarak tempuh menuju lokasi wisata kota Cirebon.

3. Para pengunjung bisa mengakses informasi mengenai jalur angkutan umum berdasarkan jarak tempuh ketika menuju lokasi wisata kota Cirebon. 


\section{BIBLIOGRAFI}

Abdurokhim, A. (2016). Analisis Komparatif Penggunaan Sistem Informasi Perbankan antara Bank Syariah aan Bank Konvensional. Syntax Literate; Jurnal Ilmiah Indonesia, 1(1), 41-54.

Arikunto, S., \& Yuliana, L. (2008). Manajemen pendidikan. Yogyakarta: Aditya Media, 11 .

Levitin, A., \& Mukherjee, S. (2007). Introduction to the design \& analysis of algorithms. Vol. 2. Pearson Addison-Wesley.

Lukman, A., \& AR, R. (2011). Nurhayati.(2011). Penyelesaian Travelling Salesman Problem Dengan Algoritma Greedy. 